\title{
Factors Affecting Dental Services Quality in the Private Sector From Patients' Perspective in Amman-Jordan
}

\author{
Jihad M. Saadeh ${ }^{1} \&$ Mohammad A. Tarawneh ${ }^{1}$ \\ ${ }^{1}$ Business School, University of Jordan, Amman, Jordan \\ Correspondence: Mohammad A. Tarawneh, Business School, University of Jordan, Amman, Jordan.
}

Received: August 10, 2020

Accepted: September 13, $2020 \quad$ Online Published: September 18, 2020

doi:10.5430/ijba.v11n5p71

URL: https://doi.org/10.5430/ijba.v11n5p71

\begin{abstract}
Introduction: The world has been rapidly evolving with a high pace towards clients' satisfaction. Service providers strive for clients' satisfaction as it has become more obvious that this is the key to maintain a growing and successful business

Objectives: The objective of this study is to investigate the relationship between the five dimensions of quality of patients' satisfaction and the quality of dental services.

Materials \& Methods: Several databases were searched for relevant articles and research papers with an objective revolving around the factors affecting client satisfaction from dental services provided at either a certain clinic, group of clinics, or had a population of a whole city. The articles and research papers covered parts of Eastern Asia, the Middle East, South/North America, and Europe.

Multiple regression analysis was performed to study this relationship. The results showed significant relationship between each of the five dimensions of quality with the following weights: Tangibility $=17.7 \%$, Empathy $=17.2 \%$, Responsiveness $=15.6 \%$, Assurance $=14.7 \%$ and Reliability $=5.8 \%$. Overall $\mathrm{R}$ square $=75.3 \%$ adjusted $\mathrm{R}$ square is $73.2 \%$ with $\mathrm{R}=0.868$.

Conclusion: The unique aspect of this study, which makes it different from other studies, is that it will not only evaluate the dental service received by patients but will also clearly state how a patient defines a good quality dental service according to their priorities to help in reaching of mutual understanding and definition of a good quality service provider.
\end{abstract}

The multiple regression models showed significant relationship between the five dimensions of quality and patients' satisfaction

Keywords: quality satisfaction, five dimensions of quality, patient satisfaction

\section{Introduction}

In the last two decades, the world has been rapidly evolving with a high pace towards clients' satisfaction. Technology advancements, high competition, and the supply-demand relationship made service providers strive for clients' satisfaction as it has become more obvious that this is the key to maintain a growing and successful business.

Developed by Parasuraman et al 1, the SERVQUAL model defined five dimensions of service quality; Assurance, Responsiveness, Reliability, Empathy, and Tangibility. The questions remain how the service receivers (patients) rank these dimensions from their point of view and to what extent the service providers (dentists) understand these rankings.

The objective of this research study is to determine the ranking of factors affecting patient satisfaction of dental services provided by the private sector in Amman- Jordan from the patients' perspective in addition to their level of satisfaction.

Evaluating patients' perceptions and beliefs about dentists can provide relevant information to suggest ways to meet patients' needs thus providing more relative quality measure by the service providers to meet patients' expectations.

After reaching a conclusion regarding this matter, results will be provided to dentists in order to narrow the gap between their understanding and patients' understanding regarding a good quality dental service. 
All the articles and research papers reviewed in this literature review have an objective revolving around the factors affecting client satisfaction from dental services provided at either a certain clinic, group of clinics, or had a population of a whole city. The articles and research papers covered parts of Eastern Asia, the Middle East, South/North America, and Europe.

Two of the above sources were articles based on a literature review of 46 and 30 other articles and research papers. Out of the remaining 13 sources, 53.8\% used the Likert Scale ranging from strongly satisfied $\{5\}$ to strongly dissatisfied $\{1\}$ to measure the patients' satisfaction from dental services received, where the remaining depended on other measures like out of 4 scales, yes or no questions, and 0 to 10 scales.

Around thirty percent $(30.1 \%)$ out of the 13 above articles and research papers relied on the 5 dimensions of quality defined by Parasuraman et al;Assurance, Responsiveness, Reliability, Empathy, and Tangibility. The rest of the studies used similar dimensions to the SERVQUAL model using similar terms that imply the same measures and obtain relative information about quality measures to determine satisfaction.

The mean sample size after eliminating outliers is 229 . The mean number of questions the researchers used in their questionnaire was 22.1 after eliminating outliers. The questions were divided mainly into 4 or 5 groups. For the studies based on the five dimensions of quality, the groups were divided accordingly. For the rest of the studies, the groups were mostly defined by environment, dentists' skills, accessibility, communication, and staff overall interaction. Only 1 of the above studies used personal interviews to fill out their questionnaires.

All the above studies used a 95\% confidence level in their research. As a rule of thumb and after taking into consideration the risk of committing a type I error, a 95\% confidence level seems the most logical to be used in these types of studies.

Depending on the nature and purpose of the study, data analysis was computed using statistical approaches like correlation, regression, chi-square, t-test, F-test, Mann-Whitney U test, CFA in addition to calculations of descriptive statistics.

The dependent variable in all articles was the patient satisfaction of the dental services provided. On the other hand, independent variables ranged between the five dimensions of quality and other factors such as environment, dentists' skills, accessibility, communication, staff overall interaction, cost, ease of booking of dental appointments, bonding, accountability, and welcoming of the patient.

All studies showed a strong relationship between the dependent variable (patient satisfaction) and the score obtained from the questionnaire which examined the independent variables mentioned above.

Newsome el al. found that patients over age of 60 were more satisfied with their dental care compared to younger patients; on the other hand younger patients were more satisfied with the level of communication established through the treatment than older patients. One study confirms that there is a positive relationship between the education level of patients and their satisfaction with the communication establish during the treatment.

According to a study conducted at the dental faculty in a university in Iran, no correlation was found between patients' age and level of satisfaction. Moreover, females under investigation showed higher satisfaction with the admission process and lower satisfaction with the dentists' behavior than males. Similarly, other researchers demonstrated that females had a greater level of satisfaction since they had more exposure to dental treatments with more frequent visits.

A study comprising patients in Riyadh city indicated that there is a positive relationship between patients satisfaction, the frequency of visits, and whether the dentist was recommended to the patient by a third party.

Using a sample size of 724, Ungureanu el al. had clear evidence to conclude that patience and respect are some of the main factors that build a positive level of satisfaction during treatment in addition to the overall quality of treatment. There is a positive relationship between the convenience of booking an appointment and the overall level of satisfaction.

According to an article published in the International Journal of Health Care Quality Assurance following the five dimensions of quality, assurance, and tangibility, respectively had the highest and lowest effects on dental service quality. On the other hand, in a study executed in Indonesia, tangibility, reliability, and assurance showed the highest effect on dental service quality while the responsiveness dimensions have the lowest effects. The results of another study that was conducted in Indonesia showed that patient satisfaction is highest in the dimension of empathy and lowest on assurance dimensions. 
Information collected at Tibah University in Saudi Arabia detected that patients with Saudi nationality had a greater level of satisfaction than Non-Saudis. This relationship can be explained by the level of communication established during treatment that may have affected the level of satisfaction. Another reason explaining this conclusion is that some Non-Saudis have higher expectations. These expectations were created by comparing the dental treatments they received outside Saudi Arabia to those received inside it.

A study which was done in Brazil focused on a larger sample compared to the other studies included in my literature review. The questionnaire included more specific questions than other studies; for example, do dentists take notes during the examination? Do they allow enough time to answer all the patients' questions and concerns? What do patients think about the condition of the technology used during the treatment? How would they rate the condition of the dental chair? The questionnaire was filled through interviews conducted by professional researchers.

An article published in a journal in the United States focused on the perspective of the patients regarding the dental services provided and the level of satisfaction. The study is a bit different from the other studies incorporated in our literature review due to the fact that the technical aspect of the treatment was included. The study shows clear evidence that the quality of the treatment is a major factor in relation to the patient's satisfaction. This includes the aesthetic result obtained from the treatment. The questionnaire included technical questions regarding a restorative treatment.

The second difference is that the demographics of the dentists were recorded to study the influence of this factor regarding the level of satisfaction perceived by the patient. The study clearly shows that opposite gender interaction reveals a lower level of satisfaction.

In contrast to the above-mentioned article, another study that was done at Candon city clearly stated that it is not possible for patients to evaluate whether the treatment was done in a perfect manner or the level of technical skills the dentist had. This is because patients often lack such professional knowledge. However, patients may evaluate other aspects of the treatment based on the aesthetic results, pain levels, and the aftercare provided by the professionals when appropriate.

\section{Problem Definition}

Mutual understanding and definition of a good quality dental service may differ between patients' point of view and professional point of view. While some dentists think that they are doing their best to provide high-quality service, they may be missing what the patients are expecting and their priorities towards receiving a satisfactory level of service.

The importance of this study is that it will indicate the level of satisfaction from patients' perspectives following the five dimensions of quality. This will enable us to provide the dentists with accurate feedback thus improving their services where appropriate.

The unique aspect of this study, which makes it different from other studies, is that it will not only evaluate the dental service received by patients but will also clearly state how a patient defines a good quality dental service according to their priorities.

Computing the results from the data collected will serve the following:

1. It will encourage dentists to maintain their level of service according to the answers provided by the patients and focus on certain areas to meet patients' expectations.

2. The results will be provided to the dentists by Transjordan for Medical Tools and Supplies as a logistic service thus meeting its dentist's expectation.

The study will be designed to find answers for the following questions:

1. What is the level of satisfaction of patients from the dental service provided?

2. What is the weight of each dimension of quality affecting the overall patient satisfaction?

Study objectives:

1. To determine the patients' level of satisfaction from the dental services provided.

2. To determine the weight of each factor of the five dimensions of quality affecting the overall patient satisfaction.

The theoretical framework of the study: 


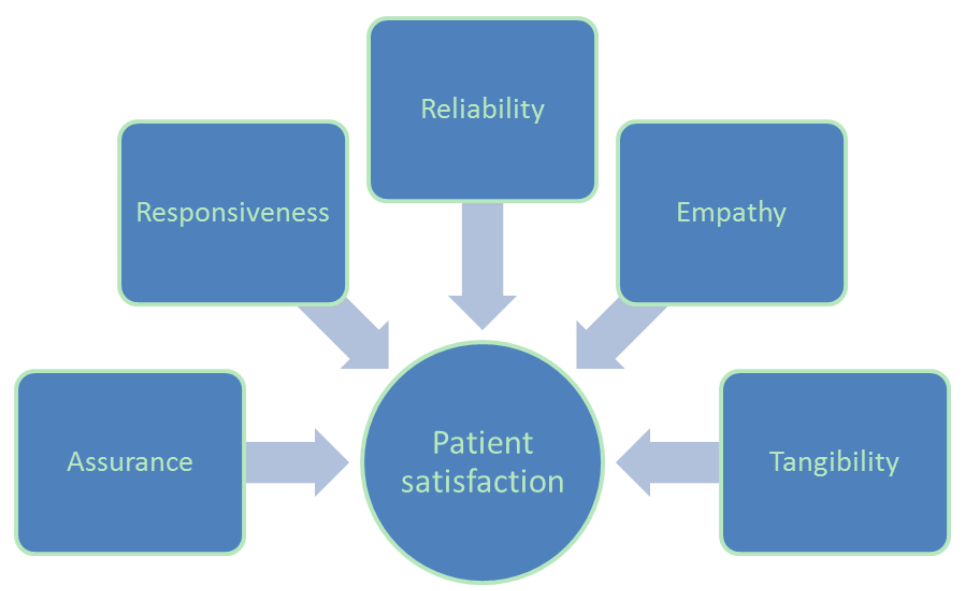

Figure 1. Study model

\section{Study Hypotheses}

\subsection{Main Hypothesis}

H0: There is no significant relationship between the five dimensions of quality and patient satisfaction.

H1: There is a significant relationship between the five dimensions of quality and patient satisfaction.

\subsection{Sub-hypotheses}

$\mathrm{H} 0$ : There is no significant relationship between assurance and patient satisfaction.

H0: There is no significant relationship between responsiveness and patient satisfaction.

H0: There is no significant relationship between reliability and patient satisfaction.

H0: There is no significant relationship between empathy and patient satisfaction.

H0: There is no significant relationship between tangibility and patient satisfaction.

\section{Operational Definitions}

Patient satisfaction about the five dimensions of the dental service quality will be measured through the following elements.

\section{Responsiveness}

a. Waiting time before the treatment

b. Aftercare of the treatment

c. Emergency availability

d. Ease of booking an appointment

e. Deal with patients' complaints in a proper manner

\section{Reliability}

a. Work should be done properly without the need for a retreatment

b. Treatment explanation

c. Fair treatment costs

d. Guarantee of treatment for a certain period of time 


\section{Tangibility}

a. Comfortable payment options with payment scheduling if needed

b. Enough car parking spaces

c. The equipment should be modern

d. Facilities should be clean and desirable

\section{Assurance}

a. Dentists should be up to date with new technologies

b. Dental clinics should have a data privacy policy

c. A dentist should be a specialist in a certain field of dentistry

d. Years of experience the dentist has

\section{Empathy}

a. Consider certain dental clinic phobias patients may have

b. Apply discounts when appropriate to meet patients' circumstances

c. Use simple scientific terms when explaining the procedure

d. Equality between patients regarding their demographic information

\section{Sampling and Distribution}

For the purpose of this paper and given the current circumstances, the independent (X) variables were randomly generated using an online application www.calculator.net/random-number-generator.

According to the survey, the patients were asked to rate their experience following the five dimensions of quality defined by Parasuraman et al. Each category of the five dimensions had four questions to be rated from 5 representing worse to 1 representing excellent using Likret scale.

The application generated 75 average random answers from 1-5 under each category and represented an average of four questions asked under a given dimension as shown in Table 1.

Table 1. Example of data generator and input of SPSS

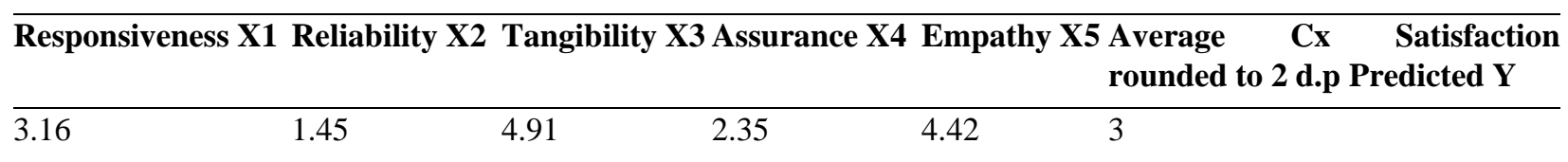

The application generated 75 rows representing the sample size. Since p-value equals $0.08>\alpha=0.05$ It is assumed that the data is normally distributed as shown in Figure 2.

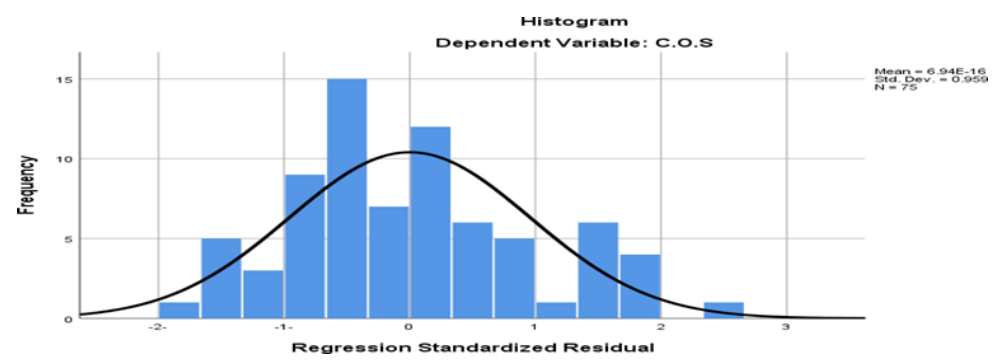

Figure 2. Normal distribution of investigated variables SPSS 


\section{Hypothesis Testing}

The main objective of this study is to examine the type of relationship between the five dimensions of quality represented by independent $\mathrm{X} 1$ to $\mathrm{X} 5$ variables, and the overall patient satisfaction dependent variable represented by Y. Moreover, the weight effect of each independent variable on the dependent variable will be examined also. The below hypothesis will be tested in order to reach a conclusion using a regression model. The model will allow us to predict the level of patient satisfaction for a given independent variable.

Responsiveness $=\mathrm{X} 1$, Reliability $=\mathrm{X} 2$, Tangibility $=\mathrm{X} 3$, Assurance $=\mathrm{X} 4$, Empathy $=\mathrm{X} 5$, Overall patient satisfaction $=\mathrm{Y}$

The analysis will be conducted at a 95\% confidence level.

\section{Correlation and Regression Model SPSS}

The first step was to insert the data generated by the application into the SPSS. The correlation between the variables was examined as a start for a sign to investigate further using regression in addition to examine whether there is any significant correlation between the independent variables that will affect our overall regression model. As shown in Table 3, a correlation matrix was computed. Four of the independent variables; Responsiveness $=\mathrm{X} 1$, Reliability $=$ $\mathrm{X} 2$, Tangibility $=\mathrm{X} 3$, Assurance $=\mathrm{X} 4$, Empathy $=\mathrm{X} 5$ showed significant correlation with the dependent variable denoted by SPSS with ** sign to be significant under $\alpha=0.01$ which is automatically significant under $\alpha=0.05$. For these four variables $0.395,0.420,0.384,0.414$ were respectively detected and marked with green in Table 3 with a positive value indicating a positive relationship with the dependent variable meaning that these variables increase and decrease relatively.

Table 2. Descriptive data input

\begin{tabular}{llll}
\hline Mean & & Std. Deviation & $\mathrm{N}$ \\
\hline C.O.S & 3.01 & .507 & 75 \\
\hline Empathy & 3.0500 & 1.14570 & 75 \\
\hline Responsiveness & 3.0821 & 1.15187 & 75 \\
\hline Reliability & 3.1123 & 1.09596 & 75 \\
\hline Tangibility & 2.9371 & 1.17558 & 75 \\
\hline Assurance & 3.0295 & 1.13625 & 75 \\
\hline
\end{tabular}

Table 3. Correlation matrix

\begin{tabular}{lllllllll}
\hline Responsiveness & & \multicolumn{2}{l}{ Reliability } & Tangibility & Assurance & Empathy & P.S (y) \\
\hline Responsiveness & $\begin{array}{l}\text { Pearson } \\
\text { Correlation }\end{array}$ & 1 & $-.105-$ & .106 & .000 & .008 & $.395^{* *}$ \\
\cline { 2 - 8 } & Sig. (2-tailed) & & .371 & .367 & .997 & .949 & .000 \\
\cline { 2 - 8 } & $\mathrm{N}$ & 75 & 75 & 75 & 75 & 75 & 75 \\
\hline Reliability & Pearson & $-.105-$ & 1 & .004 & $-.073-$ & $-.143-$ & $.240^{*}$ \\
& Correlation & & & & & & \\
\cline { 2 - 8 } & Sig. (2-tailed) & .371 & 75 & 75 & 75 & 75 & 75 & 75 \\
\hline Tangibility & N & Pearson & .106 & .004 & 1 & .016 & .015 & $.420^{* *}$ \\
& Correlation & & .973 & .536 & .220 & .038 \\
& Sig. (2-tailed) & .367 & .973 & & .889 & .898 & .000 \\
\cline { 2 - 8 } & $\mathrm{N}$ & 75 & 75 & 75 & 75 & 75 & 75 \\
\hline
\end{tabular}




\begin{tabular}{llllllll}
\hline Assurance & Pearson & .000 & $-.073-$ & .016 & 1 & $-.022-$ & $.384^{* *}$ \\
& Correlation & & & & & & \\
\cline { 2 - 8 } & Sig. (2-tailed) & .997 & .536 & .889 & & .853 & .001 \\
\cline { 2 - 8 } & $\mathrm{N}$ & 75 & 75 & 75 & 75 & 75 & 75 \\
\hline Empathy & Pearson & .008 & $-.143-$ & .015 & $-.022-$ & 1 & $.414^{* *}$ \\
& Correlation & & & & & & \\
& Sig. (2-tailed) & .949 & .220 & .898 & .853 & & .000 \\
\hline Patient & $\mathrm{N}$ & 75 & 75 & 75 & 75 & 75 & 75 \\
Satisfaction & Pearson & $.395^{* *}$ & $.240^{* *}$ & $.420^{* *}$ & $.384^{* *}$ & $.414^{* *}$ & 1 \\
& Correlation & & & & & & \\
& Sig. (2-tailed) & .000 & .038 & .000 & .001 & .000 & \\
\cline { 2 - 8 } & $\mathrm{N}$ & 75 & 75 & 75 & 75 & 75 & 75 \\
\hline
\end{tabular}

*. Correlation is significant at the 0.05 level (2-tailed).

**. Correlation is significant at the 0.01 level (2-tailed).

For the independent variable Reliability $=\mathrm{X} 2$ it is significant under $\alpha=0.05$ with a 0.24 Pearson correlation coefficient with a positive sign indicating a positive relationship. It was also observed that no significant correlation is detected among the independent variables.

Table 4. Model summary regression output SPSS

\begin{tabular}{lllll}
\hline Model R & & R Square & Adjusted R Square & Std. Error of the Estimate \\
\hline 1 & $.868 \mathrm{a}$ & .753 & .732 & .262 \\
\hline
\end{tabular}

a. Predictors: (Constant), Tangibility, Reliability, Assurance, Empathy, Responsiveness

b. Dependent Variable: C.O.S

The correlation coefficient $\mathrm{R}=0.868$ shown in Table 4 suggests a positive relationship between the independent and dependent variables and since relationship does not imply causation in the correlation determination coefficient $\mathrm{R}$ Square is computed 0.753 which implies that the predictors independent variables explains $75.3 \%$ of the variance in the dependent variable $\mathrm{Y}$ as shown in Table 4.

Table 5. ANOVA output SPSS

\begin{tabular}{lllllll}
\hline Model & & Sum of Squares & df & Mean Square & F & Sig. \\
\hline 1 & Regression & 14.304 & 6 & 2.384 & 34.623 & $.000^{\mathrm{b}}$ \\
\hline & Residual & 4.682 & 68 & .069 & & \\
\hline Total & 18.987 & 74 & & & \\
\hline
\end{tabular}

To test if the $\mathrm{R}$ square result is significant under $\alpha=0.05$, an $\mathrm{F}$ test is computed in Table 5 using the ANOVA table. A calculated value of $\mathrm{F}$ is 34.62 higher than the table value of around 4 as shown in Figure 3. This means that we reject the null hypothesis stating that all of the regression coefficients are equal to zero. 


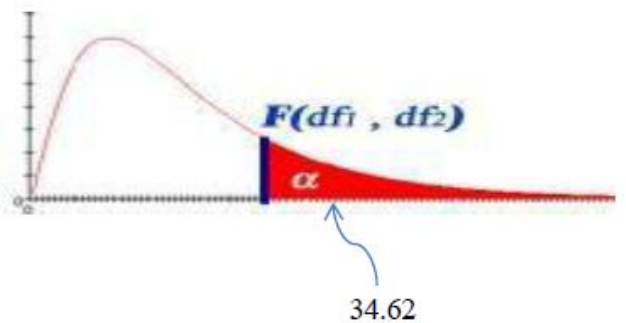

Figure 3. F Calculated 34.62 under Null Hypothesis Rejection Region

Table 6. SPSS Table of Independent Coefficients with t-test and VIF test for each

\begin{tabular}{|c|c|c|c|c|c|c|c|c|c|c|c|}
\hline \multicolumn{12}{|l|}{ Coefficients } \\
\hline \multirow[b]{2}{*}{ Model } & \multicolumn{2}{|c|}{$\begin{array}{l}\text { Unstandardized } \\
\text { Coefficients }\end{array}$} & \multirow{2}{*}{$\begin{array}{l}\text { Stand. } \\
\text { Coeff. } \\
\text { Beta }\end{array}$} & \multirow[b]{2}{*}{$\mathrm{t}$} & \multirow[b]{2}{*}{ Sig. } & \multicolumn{2}{|c|}{$95.0 \%$ C.I for B } & \multicolumn{2}{|c|}{ Correlations } & \multicolumn{2}{|c|}{$\begin{array}{l}\text { Collinearity } \\
\text { Statistics }\end{array}$} \\
\hline & B & Std. Error & & & & L Bound & U Bound & Zero-c & Partial Part & Tolerance & VIF \\
\hline 1 (Constant) & .335 & .219 & & 1.530 & .131 & $-.102-$ & .772 & & & & \\
\hline Empathy & .205 & .027 & .465 & 7.559 & .000 & .151 & 260 & .414 & .676 & .959 & 1.042 \\
\hline Responsiveness & .176 & .027 & .399 & 6.411 & .000 & .121 & .230 & .395 & .614 & .935 & 1.069 \\
\hline Reliability & .175 & .028 & .379 & 6.162 & .000 & .118 & .232 & .240 & .599 & .961 & 1.041 \\
\hline Tangibility & .156 & .026 & .362 & 5.961 & .000 & .104 & .208 & .420 & .586 & .985 & 1.015 \\
\hline Assurance & .184 & .027 & .413 & 6.808 & .000 & .130 & .238 & .384 & .637 & .986 & 1.014 \\
\hline
\end{tabular}

$$
\mathrm{Y}=0.335+0.176 \mathrm{X} 1+0.175 \mathrm{X} 2+0.156 \mathrm{X} 3+0.184 \mathrm{X} 4+0.205 \mathrm{X} 5
$$

Table 6 shows that the multiple regression equation shown above is reliable to predict the value of $\mathrm{Y}$ (patient satisfaction) for a given value of independent variables. The table also shows the t-test calculated values to be 6.411, $6.162,5.961,6.808$, and 7.559 respectively for X1 through X5 higher than t-critical 1.992.This implies that all the coefficients are significant under $\alpha=0.05$ when tested individually which is important because adding a significant variable to the model will make it more effective while adding a non-significant one will make the model worse resulting in low quality predictions. Thus, we reject the null hypothesis stating that any slope represented by the coefficients represented in our regression model is equal to zero.

Multicollinearity refers to independent variables in a regression model that can have a strong linear relationship on each other causing the R Square value to be inflated and thus resulting in bad relationship indication between independent and dependent variables. The above table also shows a variance inflation factor for each independent variable to be less than 2.5; this proves that there is no Multicollinearity between independent variables.

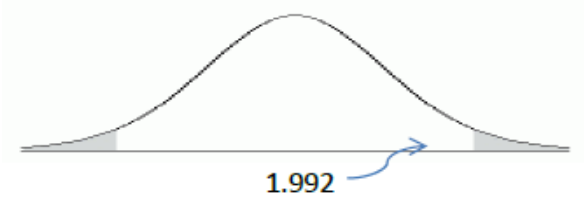

Figure 4. All t-test values computed in Table 6 fall in the rejection region 


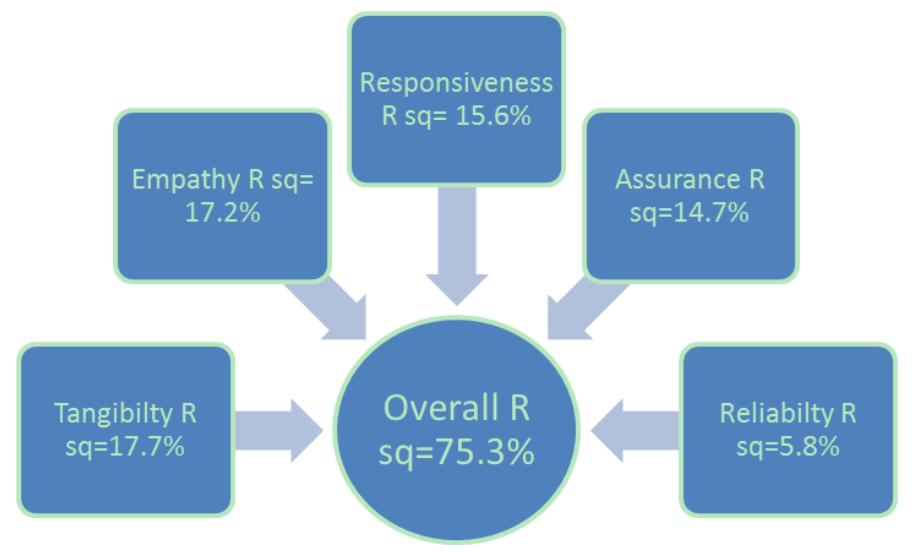

Figure 5. Comparison of individual regression output SPSS

It is especially important to compute the value of $\mathrm{R}$ square for each independent variable against the dependent variable. This will allow us to observe the weight contribution of each individual to the overall multiple regression result. Results in Figure 5 show the highest and the lowest weights. After computing the individual $\mathrm{F}$ test for each $\mathrm{R}$ square, all results showed significance under $\alpha=0.05$.

However, the reliability variable showed the lowest $R$ square in case this particular $F$ test resulted in a non-significant relationship then this should be treated by either removing this variable or combining it with other independent variables to eliminate the option of computing an inflated overall $\mathrm{R}$ square result. The summation of individual $\mathrm{R}$ square $=71 \%$ which is $4.3 \%$ lower than the result of the overall regression model. This can be explained due to the fact that this variance is a result of the partial correlation between more than one independent variable.

\section{Adjusted R Square}

Adjusted R square is considered more important than $\mathrm{R}$ square due to the fact that it only increases if we add an effective independent variable to the model. On the other hand, the $\mathrm{R}$ square will increase automatically by adding an independent variable without taking into consideration if this added independent variable is effective or not to the overall regression model. In our case, the adjusted $\mathrm{R}$ square is $73.2 \%$ compared to $75.3 \% \mathrm{R}$ square. In comparison the adjusted $\mathrm{R}$ square is closer to the summation of the individual regression results.

\section{Conclusion}

Mutual understanding and definition of a good quality dental service may differ between patients' point of view and professional point of view. The importance of this study is that it will indicate the level of satisfaction from patients' perspectives following the five dimensions of quality and convey back to the service provider (Dentists) thus helping them improving their services where appropriate.

The unique aspect of this study, which makes it different from other studies, is that it will not only evaluate the dental service received by patients but will also clearly state how a patient defines a good quality dental service according to their priorities to help in reaching of mutual understanding and definition of a good quality service provider.

The multiple regression models showed significant relationship between the five dimensions of quality and patients' satisfaction with the following weights: Tangibility $=17.7 \%$, Empathy $=17.2 \%$, Responsiveness $=15.6 \%$, Assurance $=14.7 \%$, and Reliability $=5.8 \%$. Overall $\mathrm{R}$ square $=75.3 \%$ and the adjusted $\mathrm{R}$ square is $73.2 \%$ with $\mathrm{R}=$ 0.868. Results were checked for Multicollinearity using the VIF method indicating all values to be lower than 2.5. Patient satisfaction can be reliably predicted through the equation shown in Table (6).

\section{References}

Akbar, F. H., Pasiga, B. D., Samad, R., \& Bakri, I. (2018). Patient satisfaction levels in dental health care: a case study of people in North Mamuju, Indonesia 2017. Journal of Dentomaxillofacial Science, 3(2), 116.

Akbar, F. H., Pasinringi, S., \& Awang, A. H. (2019). Factors Affecting Dental Center Service Quality in Indonesia. Research paper Published. 
Aldosari, M. A., Tavares, M. A., Matta-Machado, A. T. G., \& Abreu, M. H. N. G. (2017). Factors associated with patients' satisfaction in Brazilian dental primary health care. PLoS One, 12(11), e0187993.

Al-Hussyeen, Al. J. A. (2010). Factors affecting utilization of dental health services and satisfaction among adolescent females in Riyadh City. The Saudi Dental Journal, 22(1), 19-25.

Ali, D. A. (2016). Patient satisfaction in dental healthcare centers. European Journal of Dentistry, 10(3).

Amorin, R. C., Bal-Iyang, S. J. P., Collo, J. B. D., Joshua G. G., Jallorina, S. G., Manzano, M. A., ... Ragma, F. G. (2017). Quality of and Patients' Satisfaction on Dental Services in Candon City.

Bahadori, M. K., Abadi, M. R., Ravaged, R., \& Baldacchino, D. (2015). Factors affecting dental service quality. International Journal of Health Care Quality, 28(7), 678-689.

Balhaddad, A. A., AlShammari, A., Alqadi, A., \& Nazir, M. A. (2018). Patient Satisfaction with Dental Services and Associated Factors in a Saudi Dental Institution. Journal of Clinical and Diagnostic Research, 7(2), 104-109.

Mahrous, M. S., \& Hifnawy, T. (2012). Patient satisfaction from dental services provided by the College of Dentistry, Taibah University, Saudi Arabia. Journal of Taibah University Medical Sciences, 7(2), 104-109.

Miri, S. S., Nejad, M. M., \& Soltani, P. (2016). Evaluation of Patient Satisfaction with Dental Services at Kermanshah Dental Faculty in Iran.

Newsome, P. R. H., \& Wright, G. H. (1999). A review of patient satisfaction: 2. dental patient satisfaction: an appraisal of recent literature. British Dental Journal, 186(4).

Parasuraman, A., Ziethaml, V., \& Berry, L. L. (1985). Servqual: a multiple- item scale for measuring consumer perceptions of service quality. Journal of Retailing, 62(1), 12-40.

Riley, J. L., Gordan, V. V., Rindal, D. B., Fellows, J. L., Qvist, V., Patel, S., ... Gilbert, G. H. (2012). Components of patient satisfaction with a dental restorative visit: results from The Dental Practice- Based Research Network. Journal of the American Dental Association, 143(9), 1002-1010.

Tejo, H., Belén, R., Velásquez, C., \& Andrés, R. (2016). Patients' perceptions about dentists a literature review. Odontoestomatología, 18(27).

Ungureanu, M. I., \& Mocean, F. (2015). What do patients take into account when they choose their dentist? Implications for quality improvement. Patient Prefer Adherence, 2015(9), 1715-1720.

\section{Copyrights}

Copyright for this article is retained by the author(s), with first publication rights granted to the journal.

This is an open-access article distributed under the terms and conditions of the Creative Commons Attribution license (http://creativecommons.org/licenses/by/4.0/). 